Louisiana State University

LSU Digital Commons

Faculty Publications

Department of Biological Sciences

$5-1-2006$

\title{
Modelling responses of pine savannas to climate change and large-scale disturbance
}

\author{
Brian Beckage \\ University of Vermont \\ Louis J. Gross \\ The University of Tennessee, Knoxville \\ William J. Platt \\ Louisiana State University
}

Follow this and additional works at: https://digitalcommons.Isu.edu/biosci_pubs

\section{Recommended Citation}

Beckage, B., Gross, L., \& Platt, W. (2006). Modelling responses of pine savannas to climate change and large-scale disturbance. Applied Vegetation Science, 9 (1), 75-82. https://doi.org/10.1658/ 1402-2001(2006)9[75:MROPST]2.0.C0;2

This Conference Proceeding is brought to you for free and open access by the Department of Biological Sciences at LSU Digital Commons. It has been accepted for inclusion in Faculty Publications by an authorized administrator of LSU Digital Commons. For more information, please contact ir@lsu.edu. 


\title{
Modelling responses of pine savannas to climate change and large-scale disturbance
}

\author{
Beckage, Brian ${ }^{1 *}$; Gross, Louis J.2 \& Platt, William J. ${ }^{3}$ \\ ${ }^{1}$ Department of Botany, Marsh Life Science Building, University of Vermont, Burlington, VT 05405, USA; \\ ${ }^{2}$ Department of Ecology and Evolutionary Biology, University of Tennessee, 569 Dabney Hall, Knoxville, TN 37996-1610, USA; \\ ${ }^{3}$ Department of Biological Sciences, 202 LSB, Louisiana State University, Baton Rouge, LA 70803, USA; \\ *Corresponding author; Fax+1 8026560440; E-mail brian.beckage@uvm.edu
}

\begin{abstract}
Global warming can potentially influence ecological communities through altered disturbance regimes in addition to increased temperatures. We investigate the response of pine savannas in the southeastern United States to global warming using a simple Lotka-Volterra competition model together with predicted changes to fire and hurricane disturbance regimes with global climate change. In the southeastern United States, decreased frequency of both fires and hurricanes with global warming will shift pine savannas toward a forested state. $\mathrm{A} \mathrm{CO}_{2}$ fertilization effect that increases the growth rate of tree populations will also push southeastern landscapes from open savannas towards closed forests. Transient dynamics associated with climate driven changes in vegetation will last on the order of decades to a century. In our model, the sensitivity of savannas to relative changes in the frequency of fire versus hurricanes is linearly dependent on the growth rate and mortality of trees in fire and hurricane disturbances.
\end{abstract}

Keywords: Fire; Forest; Global warming; Grassland; Hurricane; Longleaf pine; Lotka-Volterra model; Pinus palustris.

\section{Introduction}

Global warming is expected to have a large effect on ecological communities over the next century (Houghton et al. 2001). Increasing levels of greenhouse gases in the atmosphere associated with human activities have increased global temperatures over recent decades and continued anthropogenic emissions of greenhouse gases are expected to result in a rise of global temperature between 1.9 and $7.5^{\circ} \mathrm{C}$ this century (Stott $\&$ Kettleborough 2002). Species are expected to adjust their ranges towards higher latitudes and to higher elevations in response to increasing temperatures, and some range shifts have already been observed (Thomas \& Lennon 1999; Root et al. 2003). In addition to rising temperatures, global warming is expected to change the frequency of natural disturbances such as fires and hurricanes (Dale et al. 2001). Altered distur- bance regimes could exert a strong influence on the distribution and abundance of species, resulting in rapid and dramatic changes in the structure of ecological communities.

We explore the effects of altered fire and hurricane frequency on pine savannas of the southeastern United States with the goal of understanding how global climate change will influence these communities. Pine savannas are broadly-distributed ecological communities in this region that are shaped by and are sensitive to recurrent fires and hurricanes (Platt 1999). Pine savannas are likely to be more influenced by the indirect effects of global climate change on disturbance regimes rather than directly by increasing temperatures because the most pronounced warming is expected at far northern latitudes (Zwiers 2002). Other studies that have investigated the response of forested systems to global warming have typically used complex simulation models or climate envelope approaches to predict climatedriven community change (e.g. Loehle \& LeBlanc 1996; Iverson et al. 1999; Schwartz et al. 2001). In contrast, we explore the consequences of climate change on southeastern pine savannas using a simple mathematical model. We abstract much ecological detail in the hope that we may gain general insights into community responses to altered disturbance regimes rather than precise predictions.

\section{Methods}

\section{Pine savannas}

Historically, pine savannas covered 36 million ha on the coastal plan of the southeastern U.S., but only ca. 1 million ha are estimated to remain (Anon. online). Southeastern pine savannas are characterized by widely spaced pine trees in a continuous, graminoid-dominated groundcover matrix. They have a two-layered structure with distinct ground cover and canopy layers but often lack a significant mid-story component. The overstory is usually composed of Pinus palustris (longleaf pine) except 
in southern Florida where Pinus elliottii var. densa (south Florida slash pine) is the canopy dominant. Tree density in the savanna landscape is variable, ranging from nearly treeless prairies to closed woodlands; the most common condition is a discontinuous canopy with large areas unoccupied by trees (Platt 1999; Beckage \& Stout 2000). We refer to the overstory layer as 'woody' vegetation and the ground cover layer as the 'grass' component out of convenience, recognizing that woody vegetation can occur outside of the overstory and that the ground cover contains species other than grasses (Platt et al. 2006).

Variable tree density across pine savannas is associated with differences in the frequency of fire and hurricane disturbance. Decreasing disturbance leads to increasing tree density (Veno 1976; Givens et al. 1984; Gilliam \& Platt 1999; Platt et al. 2002), as illustrated by the simple conceptual model of pineland dynamics in Fig. 1. We assume that the effects of fire and hurricane disturbance are independent, although there may be interactive effects (Platt et al. 2002). In this conceptual model, pinelands exist along a continuum of overstory density from open prairie, which lacks an overstory, to a closed forest without an understory grass layer. A savanna state where grass and trees coexist, is intermediate between these two extremes. Competition between the overstory woody vegetation and the understory grass layer is largely asymmetric; the woody vegetation suppresses the grass layer while the grass layer exerts little influence on the woody vegetation. This implies that the overstory density of pinelands will increase to the exclusion of the grass layer unless disturbance periodically reduces overstory density.

\section{Model}

We represent this simple conceptual model of pine savanna dynamics mathematically using a set of ordinary differential equations (ODE) that are an extension of the Lotka-Volterra model of species competition (Kot 2001; van Langevelde et al. 2003). This modelling approach is intended to capture the general dynamics of the system rather than fine scale patterns as a forest simulation model might reproduce. We analyse this system of equations by first locating equilibrium where both grass and woody vegetation coexist, and then examine the stability of these equilibria points, which indicates whether the system will tend to stay at these points or move away. We represent the dynamics of the overstory or woody layer with the equation:

$$
\frac{d W}{d t}=r_{w} W\left(1-\frac{W}{K_{w}}\right)-\left(M_{w f} F_{f}+M_{w h} F_{h}\right) W
$$

The left side of (1) represents the instantaneous rate of change of woody biomass $W\left(\mathrm{~g} / \mathrm{m}^{2}\right)$ in the savanna

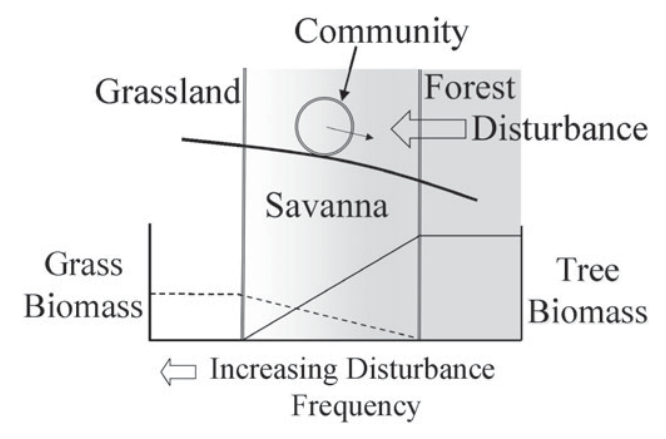

Fig. 1. Conceptual model of pine savanna dynamics in the southeastern United States. Top. The upper curved line represents the community response surface and the circle represents the location of the pineland along a hypothetical gradient from open grassland to closed forest. The pineland tends to move 'downhill' towards a closed forest in the absence of repeated disturbances such as fire. Recurring disturbances push the pineland 'upslope' toward a savanna or grassland state. Bottom. Relative amounts of grass or tree biomass along the disturbance gradient from grassland to closed forest. We define savanna as intermediate between grassland and closed forest where grass and trees occur together.

overstory. The right side of Eq. 1 consists of a growth term where the growth of woody vegetation is described by $r_{\mathrm{w}}$, which is the intrinsic rate of increase in woody biomass (1/year), and $K_{\mathrm{w}}\left(\mathrm{g} / \mathrm{m}^{2}\right)$, which is the maximum amount of woody biomass that can exist in a southeastern pineland, e.g., the carrying capacity. The growth of woody biomass is logistic, with increasing woody biomass inhibiting its continued growth. The second term on the right side of Eq. 1 describes the loss of woody vegetation due to fire and hurricane disturbances. $M_{\mathrm{wf}}$ is the proportionate loss of woody biomass in a fire and $\mathrm{F}_{\mathrm{f}}$ is the frequency of fires (1/year). Similarly, $M_{\mathrm{wh}}$ is the proportionate loss of woody biomass in a hurricane and $F_{\mathrm{h}}$ is the frequency of hurricanes (1/year).

The dynamics of the understory grass layer are described by the equation:

$$
\frac{d G}{d t}=r_{g} G\left(1-\frac{G}{K_{g}}-\frac{W}{K_{w}}\right)-M_{g} F_{f} G
$$

The left side of Eq. 2 represents the instantaneous rate of change in grass biomass $G\left(\mathrm{~g} / \mathrm{m}^{2}\right)$, while the right side contains terms for the growth and loss of grass biomass. The growth of grass biomass is again inhibited by its own growth as in equation (1) but, in addition, its growth is also reduced by increasing amounts of woody vegetation, i.e. the term

$\frac{W}{K_{w}}$.

The inclusion of this additional term in Eq. 2 but not 1 
represents the asymmetric competition between the ground layer and trees; trees shade out ground-layer vegetation but the ground layer exerts little effect on the tree layer. The right side of Eq. 2 has a loss term for fire, $M_{\mathrm{g}}$, the proportionate loss of grass biomass in a fire, but no loss term for hurricane disturbance as is found in Eq. 1. This is because hurricanes frequently blow down or snap trees, resulting in the loss of overstory biomass, but do not exert a similar effect on the ground-layer vegetation.

We simplified the analysis of this system by first non-dimensionalizing the equations to reduce the number of parameters prior to investigating their behaviour (Kot 2001). We made the following three substitutions into Eqs. 1 and 2:

$$
T=t r_{\mathrm{g}}, \quad g=\frac{G}{K_{g}}, \quad \text { and } w=\frac{W}{K_{w}}
$$

to arrive at the following simplified system of equations:

$$
\begin{aligned}
& \frac{d w}{d T}=B w(1-w)-\left(\mathrm{A}_{w}+\mathrm{A}_{h}\right) w \\
& \frac{d g}{d T}=g(1-g-w)-\mathrm{A}_{g} w
\end{aligned}
$$

where

$$
\mathrm{A}_{g}=\frac{M_{g} F_{f}}{r_{g}}, \quad \mathrm{~A}_{h}=\frac{M_{w h} F_{h}}{r_{g}}, \quad \mathrm{~A}_{w}=\frac{M_{w f} F_{f}}{r_{g}}, \quad \text { and } \mathrm{B}=\frac{r_{w}}{r_{g}}
$$

The left sides of Eqs. 3 and 4 now represent the rescaled rates of change of grass and woody vegetation. This rescaling is useful because it reduces the number of model parameters from 9 to 4 , simplifying the analysis. Note that all terms in Eqs. 3 and 4 are now dimensionless. We present results from the simplified system or from the untransformed scale as appropriate.

We analysed the system of equations to determine the location and stability of equilibrial solutions. The equilibria were found by setting both

$$
\frac{d w}{d T}=0 \quad \text { and } \quad \frac{d g}{d T}=0
$$

then solving for $w$ and $g$. The local stability of the equilibria was determined by computing the eigenvalues of the Jacobian,

$$
J=\left[\begin{array}{ll}
\frac{\partial\left(\frac{d g}{d T}\right)}{\partial g} & \frac{\partial\left(\frac{d g}{d T}\right)}{\partial w} \\
\frac{\partial\left(\frac{d w}{d T}\right)}{\partial g} & \frac{\partial\left(\frac{d w}{d T}\right)}{\partial w}
\end{array}\right]
$$

evaluated at each of the $i$ equilibrium points $\left(g_{1}, w_{1}\right) \ldots$ $\left(g_{\mathrm{i}}, w_{i}\right)$ (Kot 2001). The eigenvalues were calculated by solving the characteristic equation corresponding to

$\operatorname{Det}\left(\mathbf{J}_{i}^{*}-\lambda \mathbf{I}\right)=0$

where $\mathbf{J}_{i}^{*}$ is the Jacobian evaluated at equilibrium point $i$. The resulting eigenvalues indicate the stability of the corresponding equilibrium. An equilibrium solution is stable when the real component of both eigenvalues is $<$ 0 , unstable if the real component of either eigenvalue is $>0$, and the stability is ambiguous if one eigenvalue is $<0$ while another equals 0 . In the later case, we examined the phase plane to ascertain stability of the equilibrium. Purely imaginary eigenvalues indicate more complex dynamics. Analyses were performed using the Mathematica software (Wolfram Research, Inc.).

We investigated the transient behaviour of the system by numerically integrating the system of equations in the untransformed time scale to determine how quickly the system moved to a stable equilibrium point. This analysis required information on model parameters including intrinsic rates of increase for grass and woody vegetation $\left(r_{\mathrm{g}}, r_{\mathrm{w}}\right)$, carrying capacities $\left(K_{\mathrm{g}}, K_{\mathrm{w}}\right)$, proportionate loss of biomass in fire $\left(M_{\mathrm{g}}, M_{\mathrm{wf}}\right)$ and hurricane disturbances $\left(M_{\mathrm{wh}}\right)$, and frequencies of fires $\left(F_{\mathrm{f}}\right)$ and hurricanes $\left(F_{\mathrm{h}}\right)$. We used estimated carrying capacities from Langevelde et al. (2003), which were not specific to southeastern pine savannas, to compute intrinsic rates of increase using approximate times for grasslands and forests to reach their asymptotic biomass (Fig. 2). Estimates of loss rates in fire and hurricane disturbance come from our work in southeastern pine savannas in Florida and Louisiana as did estimates of long-term disturbance frequencies. The parameter values chosen to represent disturbance frequencies correspond to fires occurring every five years and hurricanes every 20 years, which are within the range of natural variability for these communities. The parameter values used in our analyses were, unless otherwise indicated,

$r_{g}=1.5 y r^{-1} ; \quad K_{g}=300 \mathrm{gm}^{-2} ; \quad r_{g}=0.08 y^{-1} ; \quad K_{w}=1000 \mathrm{gm}^{-2} ;$

$M_{g}=0.8 ; \quad M_{w f}=0.1 ; \quad F_{f}=0.2 y r^{-1} ; \quad M_{w h}=0.5 ; \quad F_{h}=0.05 y r^{-1}$

We emphasize that these specific values represent order of magnitude estimates of parameters that are only used to illustrate our general results. Our qualitative results do not depend on the particular values chosen.

We present results that describe the behaviour of the system of equations (1) in the absence of disturbance; (2) with only fire or hurricane disturbance, and (3) with both fire and hurricane disturbance. Since our primary interest was in describing the dynamics of existing pine savannas in response to climate change, we focused on equilibria in a savanna state. 


\section{Results}

\section{No disturbance}

In the absence of disturbance, no equilibria occurred in a savanna state with both grass and woody vegetation present. The three equilibria that did occur were located at:

$\left(g^{*}, w^{*}\right)=(0,0)(1,0)(0,1)$

The first equilibrium at $(0,0)$ corresponded to the case where neither grass nor woody vegetation was present. This was a trivial equilibrium that was unstable because any perturbation away from this point, such as the introduction of an infinitesimal amount of either grass or woody vegetation, causes the system to move increasingly far away. The second equilibrium at $(1,0)$ was in a grassland state and was also unstable, e.g., the introduction of any woody biomass results in the movement of the system toward a forest state with loss of the grass component. The third equilibrium $(0,1)$ was in a forest state and was globally stable: the system returns to the equilibrium following any perturbation away from this point.

\section{Fire disturbance}

Four equilibria occurred when fire was introduced into the system, including a trivial equilibrium with neither grass nor woody vegetation, equilibria with either grass or woody vegetation, and an equilibrium in a savanna state with both a grass and woody vegetation

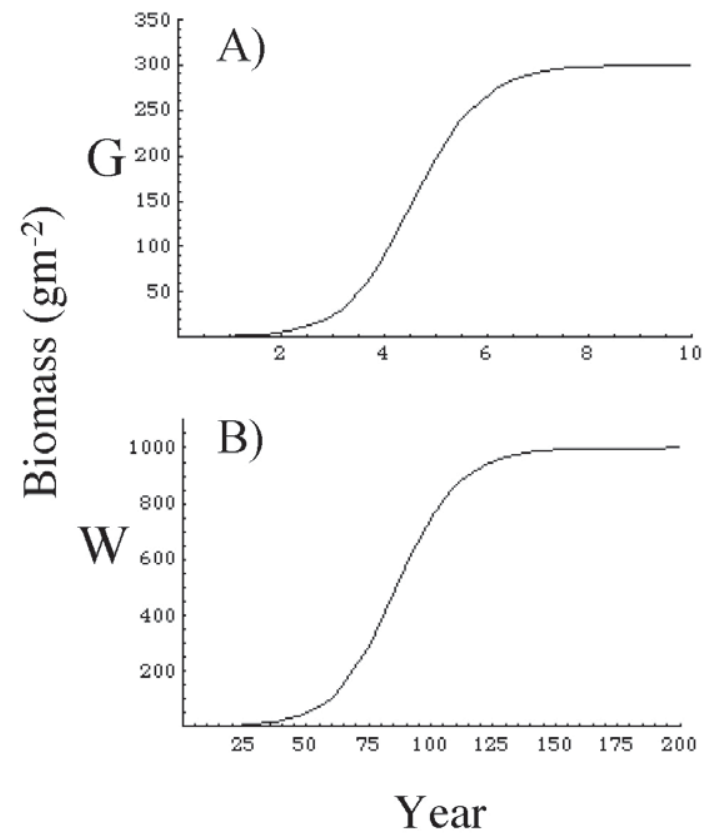

Fig. 2. Growth of (A) grass, $G$ and (B) woody, $\mathbf{W}$, biomass assuming $r_{\mathrm{g}}=1.5 . \mathrm{a}^{-1} ; \mathrm{K}_{\mathrm{g}}=300 \mathrm{~g} . \mathrm{m}^{-2} ; r_{\mathrm{w}}=0.08 . \mathrm{a}^{-1}$; and $K_{w}=1000 \mathrm{~g} \cdot \mathrm{m}^{-2}$ and beginning at $1 \%$ of carrying capacity. component. The equilibrium in the savanna state occurred at:

$$
\left(g^{*}, w^{*}\right)=\left(F_{f}\left(\frac{M_{w f}}{r_{w}}-\frac{M_{g}}{r_{g}}\right), 1-\frac{M_{w f} F_{f}}{r_{w}}\right)
$$

and was locally stable if

$$
0<F_{f}<\frac{r_{w}}{M_{w f}}<\frac{r_{g}}{M_{g}}
$$

In other words, the ratio of growth rate to fire mortality must be lower for woody vegetation compared to grass, and fires must occur at a frequency lower than these ratios for the system to exist as a savanna. If fire frequency $F_{f}$ was reduced to 0 , the savanna equilibrium collapsed to the No disturbance scenario described earlier with the system moving to a forested state.

\section{Hurricane disturbance}

Hurricane disturbance also led to four equilibria in the system. As in previous cases, three of the equilibria occurred with neither grass nor woody vegetation, with grass but no woody vegetation, or with woody vegetation but no grass component. The fourth equilibrium was in a savanna state at:

$\left(g^{*}, w^{*}\right)=\left(\frac{M_{w h} F_{h}}{r_{w}}, 1-\frac{M_{w h} F_{h}}{r_{w}}\right)$

This equilibrium was locally stable if

$0<F_{h}<\frac{r_{w}}{M_{w h}}$

If hurricane frequency $F_{\mathrm{h}}$ was reduced to 0 , the system collapsed to the No disturbance scenario and moved to a forested state. If hurricane frequency equalled or exceeded the ratio of growth rate to mortality of woody vegetation in hurricanes, then the system moved to a grassland state that lacked a woody component.

\section{Fire and hurricane disturbance}

When fire and hurricane disturbances occurred together, there were four equilibria. Three equilibria occurred outside of the savanna state and corresponded to neither grass nor woody vegetation present, grass but no woody vegetation, or woody vegetation but no grass component. The fourth equilibrium was in a savanna state with grass and woody biomass coexisting and occurred at:

$$
\left(g^{*}, w^{*}\right)=\left(\frac{M_{w h} F_{h}}{r_{w}}+\frac{M_{w f} F_{f}}{r_{w}}-\frac{M_{g} F_{f}}{r_{g}}, \frac{1}{r_{w}}\left(r_{w}-M_{w h} F_{h}-M_{w f} F_{f}\right)\right)
$$

The conditions necessary for this equilibrium to be stable were satisfied if: 


$$
F_{h}>F_{f}\left(\frac{M_{g} r_{w}-M_{w f}}{M_{w h}}\right) \quad \text { and } \quad F_{h}<\frac{r_{w}}{M_{w h}}-\frac{M_{w f} F_{f}}{M_{w h}}
$$

where both fire and hurricane frequency must be greater than 0 . The first condition was met for realistic rates of growth and mortality such as given in Eq. 5 and was satisfied by the conservative condition

$$
r_{w}<\frac{M_{w f}}{M_{g}} .
$$

The second condition states that hurricane frequency must be below a threshold described by the line:

$$
F_{h}=\frac{r_{w}}{M_{w h}}-\left(\frac{M_{w f}}{M_{w h}}\right) F_{f}
$$
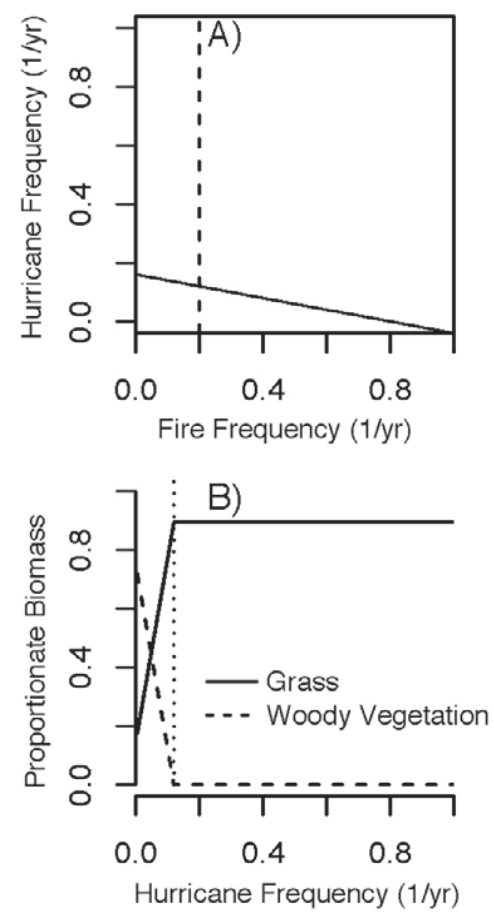

Fig. 3. Community structure as a function of fire and hurricane frequency. A. The transition from prairie to savanna. The solid line represents the threshold below which overstory trees enter the community. The system is in a prairie state with only a grass understory when above this threshold, and moves toward a forested state as disturbance frequency approaches 0 (at bottom left corner). The vertical dashed line is a slice through this response surface at a fixed fire frequency but with hurricane frequency varying from 1 (annual hurricanes) to 0 (no hurricanes). B. Proportionate abundance of grass and woody vegetation along the slice in A. The dotted vertical line indicates the location of the threshold where overstory trees begin to enter the community. At a hurricane frequency of 0 , there is still a grass understory component because fire frequency is fixed at a frequency of 0.2 (i.e. fire every five years). with intercept $\frac{r_{w}}{M_{w h}}$ and slope $\frac{M_{w f}}{M_{w h}}$.

If the frequency of disturbance is above this line (Fig. $3 a)$, then the system will be in a prairie state with no overstory present, and the further below this line the system moves, the greater the relative proportion of woody overstory compared to grass (Fig. 3b). As both fire frequency $F_{\mathrm{f}}$ and hurricane frequency $F_{\mathrm{h}}$ approach 0 , the system will move toward a closed forest. The time scale of system response is illustrated in Fig. 4. In this case the community was initially at $(g, w)=(0.46,0.44)$, which was the result of fires occurring every 5 years and hurricanes every 20 years. When the frequency of disturbance went to 0 , the system moved to the equilibrium at $(0,1)$ in 75 to 100 years (Fig. 4).

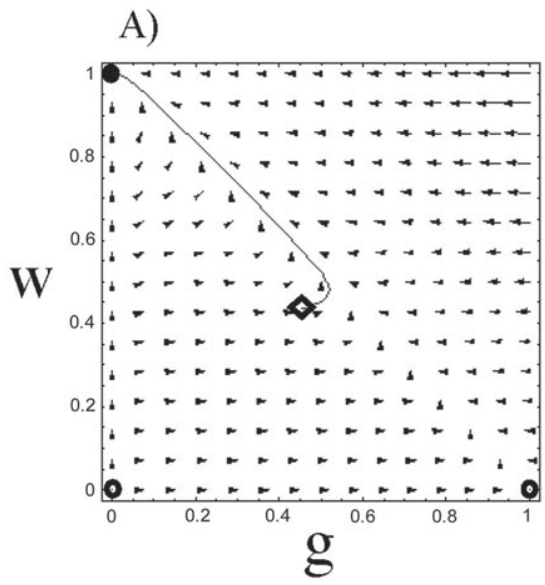

B)

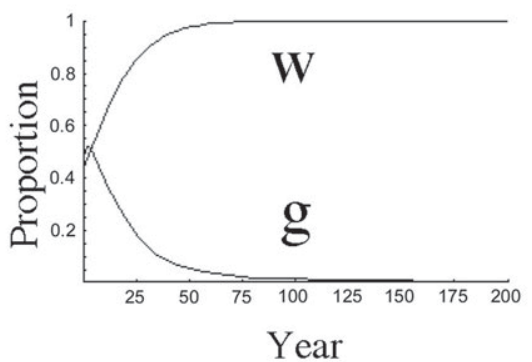

Fig. 4. Pine savanna maintained by recurrent fire and hurricane disturbances. A. Phase plane of the proportion of grass ( $g$ ) and woody vegetation $(\mathrm{w})$ with fires occurring every five years and hurricanes every 20 years. (The other parameter values are described in the Methods section.) The vectors indicate the direction and speed of change in grass and woody vegetation as a function of location in phase space. The three equilibria outside of a savanna state are indicated by circles, while the stable equilibrium in a savanna state is indicated by a diamond. If both fire and hurricane disturbances ended, the system would move along the trajectory shown from the savanna equilibrium (diamond) to a closed forest (solid circle). B. The time course of change in biomass (as a fraction of carrying capacity) is shown for grass and woody vegetation. 


\section{Discussion}

We used a variation of the Lotka-Volterra (LV) competition equations to model the dynamics of pine savannas in the southeastern U.S. in response to fire and hurricane disturbance. Systems of differential equations have been used previously to model the partitioning of soil water by grass and woody vegetation in arid savannas (e.g. Walker et al. 1981, van Langevelde et al. 2003), but these concepts are unlikely to be applicable to southeastern savannas, which tend to be more mesic. Our savanna model utilized a different model structure, which reflects the different mechanisms that operate in these wet savannas, that captured the broad patterns of pine savanna dynamics in the southeastern U.S. such as conversion from open savanna to closed forest in the absence of fire and hurricane disturbance (Veno 1976). In our model, fire or hurricane disturbances alone can lead to a stable equilibrium in a savanna state, although the location and conditions of the equilibrium are different for fire and hurricanes disturbances. This leads to the simple prediction that the cessation of fire and hurricane disturbance will result in the conversion of savannas to closed forest while the introduction of disturbance to areas that formerly lacked disturbance may result in the creation of savannas. Changes in disturbance frequency, other than the de novo introduction or elimination of disturbance, will have more complex effects on pine savannas depending on the location of the threshold where open prairies transition to savannas. As the system moves away from this threshold in the direction towards reduced levels of disturbance, the relative importance of the tree overstory increases while the understory grass component declines. The understory grass component is eliminated as the frequency of fire and hurricane disturbance approaches 0 .

In our simple model, the boundary between treeless prairies and savannas has the form of a straight line on a two-dimensional plane of disturbance frequency (Fig. 3a). The intercept of this line is determined by the growth rate and hurricane mortality of woody vegetation, while the slope is determined by the mortality of woody vegetation in fire compared to hurricanes. The sensitivity of savannas to changes in fire or hurricane frequency is determined by this slope. As fire mortality of overstory trees declines or as hurricane mortality increases, the slope of this line approaches 0 , indicating decreased sensitivity to changes in fire frequency. In contrast, increased fire mortality or declining hurricane mortality, increases the slope of the threshold indicating greater sensitivity to changes in fire frequency relative to hurricane frequency. A fertilization effect associated with elevated levels of $\mathrm{CO}_{2}$ that increases population growth rates of trees (e.g. LaDeau \& Clark 2001; Lewis et al. 2004) will move the intercept of the threshold line upward and shift communities towards a forested state even if disturbance rates remain unchanged. This predicted response is consistent with both empirical evidence of past grassland-savanna shifts associated with fluctuating atmospheric $\mathrm{CO}_{2}$ and the results of complex simulation models (Bond et al. 2003): the woody component of savannas has been reduced during past periods of low $\mathrm{CO}_{2}$ and has expanded during periods of increasing $\mathrm{CO}_{2}$ concentration.

Anticipating the effects of global warming on ecological systems requires both an understanding of community dynamics in response to external drivers such as disturbance as well as an understanding of how external drivers themselves will change. We have described the responses of pine savanna communities to altered disturbance regimes, but have not explored the expected impact of global warming on southeastern disturbance regimes. We next address how fire and hurricane disturbance regimes in the southeastern U.S. are expected to change in response to global warming before anticipating how southeastern savannas will be affected by climate change.

Global climate influences disturbance regimes in the southeastern U.S. through the periodicity and amplitude of climatic cycles such as the El Niño-Southern Oscillation (ENSO) and the North Atlantic Oscillation (NAO). These climatic cycles are characterized by atmospheric or oceanic conditions in well-defined global regions but with effects that extend globally. ENSO cycles, for example, are characterized by alternating periods of warm (El Niño phase) or cold (La Niña phase) sea surface temperatures in the central and eastern Pacific off the west coast of South America, but exert a strong influence on regional rainfall patterns and temperatures across the globe (Allan et al. 1996; Stenseth et al. 2003). In the southeastern U.S.,ENSO conditions exert a strong influence on fire regimes because of the resonance between the state of ENSO and the annual hydrologic cycle (Beckage \& Platt 2003; Beckage et al. 2003). Most rainfall is received during the summer months from convective thunderstorms with little precipitation during the winter dry season. The severity of the dry season is mediated by the state of the ENSO cycle because winter precipitation is increased during the $\mathrm{El}$ Niño phase of ENSO and decreased during the La Niña phase (Ropelewski \& Halpert 1986). In addition, the ENSO cycle influences the frequency of lightning strikes, increasing the probability of fire ignitions in years with severe La Niña droughts (Beckage et al. 2003). ENSO effects on drought conditions and lightning strike frequency result in strong concordance between the $\mathrm{La}$ Niña phase of the ENSO cycle and wildfire severity in the southeastern U.S. (Simard et al. 1985; Brenner 1991; Beckage et al. 2003). 
ENSO conditions also affect the frequency of hurricanes and tropical cyclones. Hurricanes are more frequent and intense during La Niña phases and less frequent and intense during El Niño phases (Wilson 1999; Elsner \& Bossak 2001). The incidence of hurricanes on the southeastern U.S. is also dependent on the North Atlantic Oscillation (NAO). The NAO is a north-south difference in atmospheric pressure between the subtropical high-pressure over the Azores and the subpolar low-pressure over Iceland that is related to the strength of the westerly winds in the northern Atlantic Ocean. The significance of the NAO for the southeastern U.S. is in its influence on the tracks of hurricanes and tropical cyclones. A negative NAO results in hurricanes that track predominately in a westward direction with a high likelihood of hitting the southeastern U.S. A strong positive NAO index results in increased likelihood of more northerly hurricane tracks and decreased likelihood of landfall in the southeastern U.S. ENSO and NAO events are related such that during La Niña conditions when hurricanes are most frequent, landfall in the southeastern U.S. is most probable.

Global warming is expected to affect the frequency of ENSO events, which will influence disturbance regimes in southeastern savannas. The El Niño phase of ENSO is expected to become increasingly frequent with global warming, with La Niña events decreasing in frequency (Timmermann et al. 1999; Tsonis et al. 2003). These changes to the ENSO cycle will create conditions that favour less frequent large-scale fires and decreased

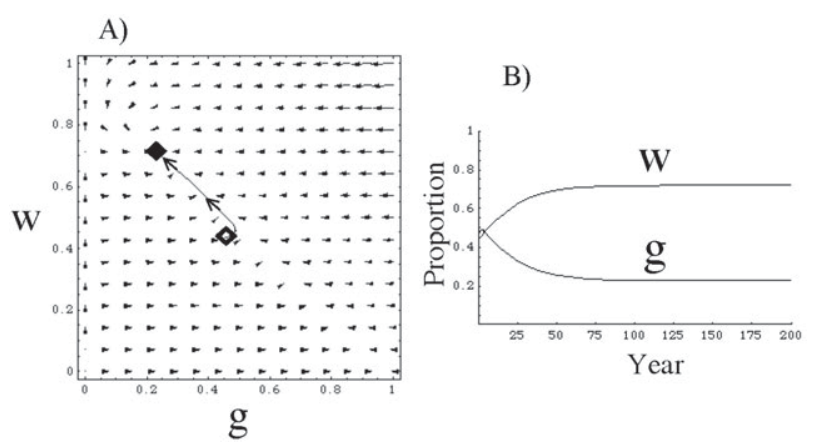

Fig. 5. Pine savanna response to a reduction in the frequency of fire and hurricane disturbances associated with global climate change. We illustrate potential changes in savanna structure associated with a decline in fire return intervals from every five years to every ten years and in hurricane return intervals from every 20 years to every 40 years. A. Phase plane of grass $(\mathrm{g})$ and woody vegetation (w) showing the trajectory of the savanna as it moves toward a more forested state in response to the decline in disturbance frequency. The open diamond indicates the initial position of the system while the solid diamond indicates the final position of the system. B. The time course of change in biomass (as a fraction of carrying capacity) is shown for grass and woody vegetation. hurricane frequency in southeastern savannas. In addition, if the current relationship between ENSO and NAO remains intact with global warming, then the hurricanes that do form will be more likely to track toward the northeastern rather than the southeastern coast of the U.S..

Reductions in the frequency of fires and hurricanes associated with global warming will push southeastern pine savannas towards a forested state with an increased overstory density and reduced understory component. If decreased fire frequency is associated with a corresponding increase in fire intensity that results in an elevated level of tree mortality, this may partially offset reduced frequency of fire. However, the overall effect of reductions in fire and hurricane frequencies in the southeastern U.S., together with a $\mathrm{CO}_{2}$ fertilization effect, will be to move savanna communities towards closed forests. If we assume that the frequency of disturbance is reduced by half, for example, with fires occurring every ten years rather than every five years and hurricanes every 40 years rather than every 20 years, then the system will move from an equilibrium at $\left(g^{*}, w^{*}\right)=$ $(0.46,0.44)$ to one at $(0.23,0.72)$ in ca. 75 years (Fig. 5$)$. The transformation of savannas to a more closed forest will have large effects on species diversity in the southeastern U.S.. Savanna understories are rich reservoirs of biodiversity (Platt 1999), which will be at risk in a warmer world with fewer large-scale disturbances, as the closing of the overstory canopy leads to large reductions in species richness in these systems (Platt et al. 2004). Preservation of southeastern savanna communities will likely require active management to offset reduced frequencies of natural disturbance.

Acknowledgements. Brian Beckage is grateful for the financial support of the National Science Foundation (Award DBI0107553) and the National Parks Ecological Research Fellowship Program, a program funded by the National Park Foundation through a generous grant from the Andrew W. Mellon Foundation. Louis Gross appreciates the support of National Science Foundation Award DMS-0110920 to the University of Tennessee.

\section{References}

Anon. [Online]. The Longleaf alliance. Available: http: // www. Longleafalliance.org

Allan, R.J., Lindesay, J. \& Parker, D.E. 1996. El Niño southern oscillation and climatic variability. CSIRO Publishing, Collingwood, Victoria, AU.

Beckage, B. \& Platt, W.J. 2003. Predicting severe wildfire years in the Florida Everglades. Front. Ecol. Environ. 1: 235-239.

Beckage, B. \& Stout, I.J. 2000. The effects of repeated burning 
on species richness in Florida sandhills: A test of the Intermediate Disturbance Hypothesis. J. Veg. Sci. 11: 113-122.

Beckage, B., Platt, W.J., Slocum, M.G. \& Panko, B. 2003. Influence of the El Niño-Southern Oscillation on fire regimes in the Florida Everglades. Ecology 84: 3124-3130.

Bond, W.J., Midgley, G.F. \& Woodward, F.I. 2003. The importance of low atmospheric $\mathrm{CO}_{2}$ and fire in promoting the spread of grasslands and savannas. Global Change Biol. 9: 973-982.

Brenner, J. 1991. Southern Oscillation anomalies and their relation to Florida wildfires. Intern. J. Wildl. Fire 1: 73-78.

Dale, V.H., Joyce, L.A., McNulty, S., Neilson, R.P., Ayres, M.P., Flannigan, M.D., Hanson, P.J., Irland, L.C., Lugo, A.E., Peterson, C.J., Simberloff, D., Swanson, F.J., Stocks, B.J. \& Wotton, B.M. 2001. Climate change and forest disturbances. Bioscience 51: 723-734.

Elsner, J.B. \& Bossak, B.H. 2001. Bayesian analysis of U.S. hurricane climate. J. Clim. 14: 4341-4350.

Gilliam, F.S. \& Platt, W.J. 1999. Effects of long-term fire exclusion on tree species composition and stand structure in an old-growth longleaf pine forest. Plant Ecol. 140: 1526.

Givens, K.T., Layne, J.N., Abrahamson, W.G. \& WhiteSchuler, S. C. 1984. Structural changes and successional relationships of five Florida Lake Wales Ridge plant communities. Bull. Torrey Bot. Club 111: 8-18.

Houghton, J.T., Ding, Y., Griggs, D.J., Noguer, M., Van der Linden, P.J. \& Xiaosu, D. 2001. Climate change 2001: The scientific basis. Cambridge University Press, Cambridge, UK.

Iverson, L.R., A. Prasad, and M. W. Schwartz. 1999. Modeling potential future individual tree-species distributions in the eastern United States under a climate change scenario: a case study with Pinus virginiana. Ecol. Model. 115: 7793.

Kot, M. 2001. Elements of mathematical ecology. Cambridge University Press, Cambridge, UK.

LaDeau, S.L. \& Clark, J.S. 2001. Rising $\mathrm{CO}_{2}$ levels and the fecundity of forest trees. Science 292: 95-98.

Lewis, S.L., Phillips, O.L., Baker, T.R., Lloyd, J., Malhi, Y., Almeida, Y., Higuchi, N., Laurance, W.F., Neill, D.A., Silva, J.N.M. , Terborgh, J., Torres Lezama, A., Vásquez Martinez, R., Brown, S., Chave, J., Kuebler, C., Núñez Vargas, P. \& Vinceti, B. 2004. Concerted changes in tropical forest structure and dynamics: evidence from 50 South American long-term plots. 2004. Philos. Trans. R. Soc. Lond. B Biol. Sci. 359: 421-436.

Loehle, C. \& LeBlanc, D. 1996. Model-based assessments of climate change effects on forests: a critical review. Ecol. Model. 90: 1-31.

Platt, W.J. 1999. Southeastern pine savannas. In: Anderson, R.C., Fralish, J.S.\& Baskin, J. (eds.) The savanna, barren, and rock outcrop communities of North America, pp. 2351. Cambridge University Press, Cambridge, UK.

Platt, W.J., Beckage, B., Doren, B. \& Slater, H. 2002. Interactions of large-scale disturbances: prior fire regimes and hurricane-induced mortality of savanna pines. Ecology 83: 1566-1572.

Platt, W.J., Carr, S.M., Reilly, M. \& Fahir, J. 2006. Pine savanna overstory influences on ground cover biodiversity. Appl. Veg. Sci. 9: 37-50 (this issue).

Root, T.L., Price, J.T., Hall, K.R., Schneider, S.H., Rosenzweig, M.L. \& Pounds, J.A. 2003. Fingerprints of global warming on wild animals and plants. Nature 421: 57-60.

Ropelewski, C.F. \& Halpert, M.S. 1986. North American precipitation and temperature patterns associated with the El Niño/Southern Oscillation (ENSO). Monthly Weather Rev. 114: 2352-2362.

Schwartz, M.W., Iverson, L.R. \& Prasad, A.M. 2001 . Predicting the potential future distribution of four tree species in Ohio using the current habitat availability and climatic forcing. Ecosystems 4: 568-581.

Simard, A.J., Haines, D.A. \& Main, W.A. 1985. Relations between El Niño/Southern Oscillation anomalies and wildland fire activity in the United States. Agricult. For. Meteorol. 36: 93-104.

Stenseth, N.C., Ottersen, G., Hurrell, J.W., Mysterud, A., Lima, M., Chan, K.S., Yoccoz, N.G. \& Adlandsvik, B. 2003. Studying climate effects on ecology through the use of climate indices: the North Atlantic Oscillation, El Nino Southern Oscillation and beyond. Proc. R. Soc.Lond.Ser. B Biol. Sci. 270: 2087-2096.

Stott, P.A. \& Kettleborough, J.A. 2002. Origins and estimates of uncertainty in predictions of twenty-first century temperature rise. Nature 416: 723-726.

Thomas, C.D. \& Lennon, J.J. 1999. Birds extend their range northwards. Nature 399: 213.

Timmermann, A., Oberhuber, J., Bacher, A., Esch, M., Latif, M. \& Roeckner, E. 1999. Increased El Niño frequency in a climate model forced by future greenhouse warming. Nature 398: 694-697.

Tsonis, A.A., Hunt, A.G. \& Elsner, J.B. 2003. On the relation between ENSO and global climate change. Meteorol. Atmosph. Phys. 84: 229-242.

van Langevelde, F., de Vijver, C.A.D.M., Kumar, L., de Koppel, J.V., de Ridder, N., van Andel, J., Skidmore, A.K., Hearne, J.W., Stroosnijder, L., Bond, W.J., Prins, H.H.T. \& Rietkerk, M. 2003. Effects of fire and herbivory on the stability of savanna ecosystems. Ecology 84: 337350 .

Veno, P.A. 1976. Successional relationships of five Florida plant communities. Ecology 57: 498-508.

Walker, B.H., Ludwig, D., Holling, C.S. \& Peterman, R.M. 1981. Stability of semi-arid savannah grazing systems. $J$. Ecol. 69: 473-498.

Wilson, R.M. 1999. Statistical aspects of major (intense) hurricanes in the Atlantic basin during the past 49 hurricane seasons (1950-1998): Implications for the current season. Geophys. Res. Lett. 26: 2957-2960.

Zwiers, F.W. 2002. The 20-year forecast. Nature 416: 690691.

Received 28 July 2004; Accepted 9 June 2005

Co-ordinating Editor: F.S. Gilliam. 